under high pressure, could occur in several different crystalline forms.

In his search for generalizations concerning the equilibria between solids and liquids, Tammann carried out investigations on supercooled liquids, and these led to fundamental discoveries on the nature of glasses. He measured the rates of crystallization and rates of appearance of nuclei in supercooled liquids, and correlated these properties with the rate of development of heat and the changes in viscosity that occurred. His work on silicates in the crystalline and amorphous conditions has also been of value in pointing the way for the development of geochemical and geophysical ideas.

Tammann is, perhaps, best known for his work on metallography, for the reason that this branch of his activities has had the more immediate practical application. Combining microscopical investigation with the determination of the melting point curves of metallic systems, he laid bare the secrets of many two- and three-component systems, and many intermetallic compounds. He investigated the internal structures of metallic alloys, their electrical and magnetic properties and the changes in properties which occur on cold working and during recrystallization. His work on the amorphous state led him to appreciate the significance of order and disorder in the crystalline state, and he was the first to show that the chemical properties of solid solutions were dependent on the arrangement of the atoms in the lattice. His conclusions in this field have formed the basis of much modern theoretical work, and have proved of very great significance in the metallurgical industries.

As a teacher of physical and inorganic chemistry, Tammann's influence has permeated the scientific world. Throughout a very long life, he had a very large research school, in which were represented many students from far afield, and his monographs under the titles "Kristallisieren und Schmeltzen", "Metallographie" and "Aggregatzustände" led to many developments in other hands. His interest in chemical industry was shown by the numerous technological discussions in which he took part, and by the trend of his metallographical work. He played a very active part in the development of the Zeitschrift für physikalische Chemie, the Zeitschrift für anorg. anische Chemie and the Bunsen Gesellschaft. His work was recognized by numerous honours both at home and abroad, and in his seventy-fifth year he was awarded the Adlerschild of the German Reich, with the inscription "Altmeister der Deutschen Metallurgie". By future generations, he will be remembered by his contributions to the development of the practical arts, and in this respect he deserves to rank with Agricola, the renowned metallurgist of the sixteenth century.

W. E. G.

\section{Dr. J. E. R. Constable}

The sudden death of Dr. J. E. R. Constable on February 3 came as a great shock to his friends. Dr. Constable, who was only thirty-two years old, was a senior scholar at Trinity College, Cambridge, and obtained first class in both Parts I and II of the Natural Sciences Tripos. Thereafter, he spent three years as a research student at the Cavendish Laboratory, mainly devoting himself to the application of electrical methods of detecting single particles, in the study of the artificial disintegration of the elements, work necessitating much patience and sound judgment. This investigation brought him his Ph.D.

In 1931, Constable joined the staff of the National Physical Laboratory, where he was attached to the Sound Section of the Physics Department. He soon proved himself a valuable member of the team of acoustical workers who were endeavouring to unravel the entangled phenomena associated with building acoustics, more particularly as regards the transmission and abatement of noise, both air-borne and impact.

Constable was an ingenious and all-round physicist with an original and receptive outlook. His energy and enthusiasm were contagious: he had a great aptitude for getting things done, and could speedily improvise effective equipment and demonstrations. He revealed a cheery and agreeable freshness of style when lecturing or expounding a paper. When he died, as he did in full harness, he had a book approaching completion; and some twenty published papers and articles, singly or jointly, stood to his credit, most of them relating to building acoustics. One may perhaps refer to his valuable and eminently practical investigations on the optimum sound insulation of double windows and composite partitions; the influence of the obliquity of an incident sound beam on the insulating value of a solid partition ; the vibration patterns of walls when transmitting sound; the flanking conduction of sound from room to room in a building; and the reduction of noise transmitted along water pipes.

There was assuredly a successful career in front of Constable, had he been spared. I write with a sense of keen personal loss, for we had done much together. This loss is shared by all his colleagues, who will long remember with affection his frank and friendly disposition and his very likeable personality. We offer our profound sympathy to his widow who, herself a former research student at the Cavendish Laboratory, actively co-operated in her husband's acoustical interests. There is one young son.

\section{G. W. C. KaYE.}

WE regret to announce the following deaths:

Prof. Karl Schröter, emeritus professor of botany in the Federal College of Technology, Zurich, aged eighty-four years.

Prof. A. Smithells, C.M.G., F.R.S., emeritus professor of chemistry in the University of Leeds, director of the Salters' Institute of Industrial Chemistry during 1923-1937, on February 8, aged seventy-eight years.

Prof. S. P. L. Sörensen, director of the Chemical Department of the Carlsberg Laboratory, Copenhagen, honorary fellow of the Chemical Society, aged seventy-one years. 